\title{
Publisher Correction: Estimating temperatures of heated Lower Palaeolithic flint artefacts
}

Aviad Agam (D), Ido Azuri (iD, Iddo Pinkas (D), Avi Gopher and Filipe Natalio (D)

Correction to: Nature Human Behaviour https://doi.org/10.1038/s41562-020-00955-Z, published online 5 October 2020.

In the version of this article initially published, reference 22 was provided incorrectly. It should have read: Boaretto, E. et al. Specialized flint procurement strategies for hand axes, scrapers and blades in the Late Lower Paleolithic: $\mathrm{a}^{10} \mathrm{Be}$ study at Qesem Cave, Israel. Human Evolution (Firenze) 24, 1-12 (2009). The error has been corrected in the PDF and HTML versions of this article.

Published online: 26 November 2020

https://doi.org/10.1038/s41562-020-01017-0

(c) The Author(s), under exclusive licence to Springer Nature Limited 2020 